\title{
ARTYKUŁY
}

Klio. Czasopismo poświęcone dziejom Polski i powszechnym

PL ISSN 1643-8191, t. 30 (3)/2014, s. 51-58

(c) (1) $\Theta$

http://dx.doi.org/10.12775/KLIO.2014.043

\section{Matgorzata Pawlak}

(Wrocław)

\section{Przyczynek do obrazu elit południowoapulijskich}

W pracy poświęconej rodom senatorskim wywodzącym się z połudem z Canusium, jeden z Herdonii, trzy z Lucery, dziewięć z Venusium i dwa z Brundisium ${ }^{1}$. Zdecydowana większość z wymienionych pochodziła więc zpółnocnej części regionu i praktycznie nie ma wśród nich reprezentantów Półwyspu Salentyńskiego. Wyjaśnienie owej dysproporcji kryje się niewątpliwie w skomplikowanej przeszłości italskiego południa. Od drugiego tysiąclecia p.n.e. zamieszkiwały je plemiona Apulów przybyłych na te tereny najprawdopodobniej z rejonu Ilirii². Północną część zajęli Dauniowie, środkową - Peuketowie, a Półwysep Salentyński stał się ziemią Messapiów. Stworzyli oni oryginalną kulturę, która po przybyciu na te tereny Greków (a zwłaszcza po założeniu Tarentu) uległa stopnio-

${ }^{1}$ G. Camodeca, Ascesa al senato e rapporti con i territori d'origine. Italia. Regio I (Campania esclusa la zona di Capua e Cales), II (Apulia et Calabria), III (Lucania et Bruttii), [w:] Epigrafia e Ordine senatorio, t. II, Roma 1982, s. 131-147.

2 Szerzej zob.: C. Daquino, I Messapi. Il Salento prima di Roma, Lecce 1999, s. $37-73$. 
wej hellenizacji. Charakter kontaktów spowodował, że nie była ona całkowita - tubylcy świadomie wykorzystywali greckie zdobycze cywilizacyjne (na przykład adaptując grecki alfabet do zapisu własnego języka), nie rezygnując przy tym $\mathrm{z}$ własnych tradycji. Zachowały się one zwłaszcza $\mathrm{w}$ urbanistyce, rytach pogrzebowych czy w sferze religijnej. W konfrontacji z Grekami potrafili jednak Messapiowie obronić swoją niezależność polityczną, co zaowocowało ustaleniem równorzędnych relacji ${ }^{3}$, a ostatecznie wręcz sojuszem grecko-messapijskim przypieczętowanym braterstwem broni w czasie walk z Rzymem. Wraz z italskimi Grekami ulegli też (w latach 267-266 p.n.e.) rzymskiej dominacji ${ }^{4}$. Jednym z motywów działań wojennych przeciwko Messapiom, obecnym już w rzymskiej historiografii, była chęć zdobycia Brundisium - ważnego portu i ośrodka handlowego południa Italii ${ }^{5}$. Założona tam w 244 roku p.n.e. kolonia ${ }^{6}$ stała się symbolem i gwarantem rzymskiej dominacji w regionie. Właśnie z Brundisium pochodzi jedyny, odnotowany przez Camodecę, ród senatorski bliżej związany z obszarem Messapii - Fabii Hadriani ${ }^{7}$. Reprezentuje go C. Fabius C. f. Hadrianus, którego imię widnieje w napisie honoryfikacyjnym wśród dekurionów Brundisium ${ }^{8}$. Przedstawiciele tej rodziny są poświadczeni w materiale inskrypcyjnym od I wieku p.n.e. do II wieku n.e. ${ }^{9}$, lecz największe

${ }^{3}$ M. Pawlak, Messapiowie. Potudniowa Apulia wobec hellenizacji $i$ romanizacji, Kraków 2012, s. 213-241.

${ }^{4}$ Fasti consulares et triumphales, ed. A. Degrassi, Inscriptiones Italiae, t. XIII, fasc. 1, Roma 1947, s. 73, 75, 113, 115.

${ }^{5}$ Dio, Hist. Rom., 10, ap. Zonar., Epit. Hist., 8.7.3.

${ }^{6}$ Liv., Per. 19; Cic., Att., 4.1.4; Vell. Paterc., Hist. Rom., 1.14.8.

${ }^{7}$ G. Camodeca, Ascesa al senato..., s. 141. Wydaje się, że drugi przywoływany przez autora przykład rodu senatorskiego z Brundisium (Herennii) słusznie uważa on za wątpliwy. Zob.: też M. Silvestrini, Le "élites" municipali dei Gracchi a Nerone: Apulia e Calabria, [w:] Les élites municipales de l'Italie péninsulaire des Gracques à Néron. Actes de la table ronde internationale de Clermont-Ferrand (1991), Naples-Rome 1996 (Coll. EFR, 215), s. $31-46$.

${ }^{8} \mathrm{CIL} \mathrm{I}^{2}, 3173=\mathrm{AE} 1959,272$. A. Degrassi datuje inskrypcję na ok. 40 r. p.n.e. (Un nuovo decreto municipal di Brindisi, w: Atti del terzo Congresso internazionale di Epigrafia greca e lataina, Roma 1959, s. 303-312).

${ }^{9}$ CIL IX, 111; NSA 1883, 256b, 520c; NSA 1892, 242, n. 1; AE 1978, 153. 
sukcesy w służbie publicznej odnosili jeszcze w okresie republikańskim ${ }^{10}$. Wspomniany C. Fabius Hadrianus pełnił funkcję pretora i propretora Afryki w latach 84-83 p.n.e. ${ }^{11}$. Prawdopodobnie jego (lub jego syna) wspomina inskrypcja z Delos ${ }^{12}$. Z kolei niejaki M. Fabius Hadrianus pojawia się jako legat Lukullusa w czasie wojny z Mitrydatesem (72-68 p.n.e.), a jego syn - C. Fabius M. f. Hadrianus jako pretor (58 p.n.e.) i prokonsul Azji (57-56 p.n.e. ${ }^{13}$. Brundisium posiadało jednak wyraźną specyfikę - jako ważne miasto portowe Italii stanowiło silny magnes dla kapitału pochodzącego z innych części półwyspu. Zresztą dla wielu italskich przedsiębiorców nie było jedynym miejscem prowadzenia działalności ekonomicznej. W I wieku p.n.e. wyraźnie widoczna jest tam aktywność rodzin napływowych. Elementem diagnostycznym tego zjawiska stał się wzrost produkcji amfor wytwarzanych na obszarze ager Brundisinus. Ich stemple pozwolity na identyfikację kilkudziesięciu producentów, wśród których pojawiają się przedstawiciele rodów senatorskich wywodzących się z Kampanii, Lacjum czy Etrurii ${ }^{14}$. Jeśli więc zaakceptuje się brudyzyjskie pochodzenie rodziny Fabii Hadriani, nie oznacza to wcale, że mamy do czynienia z tubylcami. Najpewniej owi Fabiusze należeli do grupy przybyszów, jacy osiedlili się tam po rzymskim podboju. Podobnie zresztą było zapewne w przypadku innych rodów senatorskich o apulijskiej proweniencji.

Lucera była pierwszą rzymską kolonią założoną w Apulii. Według Liwiusza jej ustanowienie (w 315 roku p.n.e.) zostało poprzedzone długimi walkami zakończonymi zdobyciem miasta i całkowitą eksterminacją mieszkańców. Zgodnie z uchwałą senatu zasiedliła je grupa 2500 nowych osadników ${ }^{15}$. Także podczas drugiej wojny z Samnitami zdobyli

${ }^{10}$ F. Münzer, s.v. Fabius, [w:] RE VI, 2, 1909, n. 17, col. 1744-1746; n. 81-83, col. 1771.

11 E. Badian, Notes on Roman Senators of the Republic, „Historia” 1963, 12, s. 33; T. P. Wiseman, New Men in the Roman Senate 139 B.C. - 14 A.D. , Oxford 1971, s. 230.

${ }^{12}$ I. Délos, 2009; T. R. S. Broughton, The Magistrates of the Roman Republic III, Supplement, Atlanta 1986, s. 86.

${ }^{13}$ F. Münzer, loc. cit.

${ }^{14}$ M. Silvestrini, Le »élites" municipali..., s. 34-35. Zob. też: M. Silvestrini, Le città della Puglia romana. Un profilo sociale, Scavi e ricerche 15, Bari 2005, s. 131-148.

15 Liv. 9. 26; A. V. Sirago, Puglia romana, Documenti e studi 13, Bari 1993, s. 47. 
Rzymianie daunijskie miasto Venosę (w dolinie rzeki Ofanto, na pograniczu apulijsko-samnicko-lukańskim), którego mieszkańcy podzielili zapewne los Luceran ${ }^{16}$. Ich miejsce zajęło w 291 roku p.n.e. 20 tysięcy kolonistów przysłanych z Rzymu ${ }^{17}$. Rdzenni mieszkańcy nie uchowali się też w daunijskiej Herdonii. W czasie drugiej wojny punickiej, po zdobyciu miasta przez Hannibala zostali wysiedleni do Metapontu i Turioi ${ }^{18}$. Nieco odmienna była sytuacja Canusium, które jeszcze przed zdobyciem Lucery dobrowolnie poddało się Rzymowi ${ }^{19}$, pozostając mu wierne także w czasie wojny z Hannibalem. Przypadek tego miasta jest jednak nieco zbliżony do Brundisium - jako dawna „stolica” Dauniów stało się jeszcze przed rzymskim podbojem ważnym ośrodkiem gospodarczym całej Apulii i głównym centrum produkcji ceramicznej. Zawsze chętnie osiedlali się tam więc obcy przybysze (na przykład pochodzący z Tarentu wytwórcy luksusowej greckiej ceramiki). Włączenie w rzymski system gospodarczy dodatkowo podniosło jego atrakcyjność, przyciągając inwestorów i kupców z pozostałej części półwyspu.

Napływ żywiołu italskiego do Apulii przyśpieszyła akcja osadnicza podjęta po zakończeniu drugiej wojny punickiej ${ }^{20}$. Wraz z weteranami Scypiona docierały na południe nowe grupy osiedleńców zmieniające tamtejszą strukturę etniczną. Przekształcenia te objęły zapewne przede wszystkim północne i środkowe rejony Apulii, choć brak danych źródłowych, które pozwoliłyby określić skalę tego zjawiska także dla okresu republiki i pryncypatu ${ }^{21}$. Niejednoznaczne są również przekazy dotyczące chronologii i zakresu rzymskiej centuriacji obszaru. Zdają się one jednak wskazywać, że proces ów przebiegał za czasów Wespazjana ${ }^{22}$. Jeśli chodzi

${ }^{16}$ A. V. Sirago, Puglia romana..., s. 46-47, 55.

17 Dionys. Halic. 17.5; Hor., Sat., 2.35-39; Vell., Paterc., 1.14.

18 Liv. 27. 1.

19 Liv. 9. 20.

${ }^{20}$ Liv. 31. 4; 31. 49.

${ }^{21}$ F. Grelle, Ordinamento municipale e organizzazione territoriale nella Puglia romana, [w:] L'incidenza dell'antico. Studi in memoria di Ettore Lepore, ed. A. Storchi Marino, t. I, Napoli 1995-1996 s. 242; M. Pawlak, Messapiowie...., s. 266.

${ }^{22}$ F. Chiocci, Osservazioni sulla centuriazione del Salento, [w:] Metodologie di catalogazione dei beni archeologici, Beni Archeologici, Conoscenza e tecnologie, quaderno 1.2, Lecce-Bari 1997 s. 166-175; M. Pawlak, Messapiowie..., s. 272-273. 
o strukturę własności ziemskiej w Salento, istnieją zresztą dwie równoprawne hipotezy. Wedle pierwszej z nich ziemie Messapiów były krajem całkowicie skolonizowanym, w którym dominowały wielkie latyfundia należące do rzymskiej arystokracji i zarządzane przez wyzwoleńców rezydujących w Brundisium ${ }^{23}$. Według drugiej natomiast własność majątkowa na terenie Półwyspu Salentyńskiego była znacznie bardziej rozdrobniona niż w pozostałych częściach Apulii ${ }^{24}$. Obie te teorie równie dobrze, choć w odmienny sposób, tłumaczą nieobecność tamtejszych mieszkańców w rzymskich kręgach senatorskich. Badania Camodeci wyraźnie wskazują zresztą na stosunkową słabość wczesnego osadnictwa także wpółnocnej części regionu. Przedstawiciele pierwszej rzymskiej kolonii w Apulii - Lucery pojawili się w senacie dopiero w czasach Augusta. Na ten okres przypada też awans do stanu senatorskiego trzech rodów kanozyńskich ${ }^{25}$. Obecność w senacie pierwszego rodu z Venusium, tak licznie zasiedlonego w początkach III wieku p.n.e. rzymskimi kolonistami można datować na okres panowania Klaudiusza bądź Nerona ${ }^{26}$.

To, co nie udało się przybyszom, nie powiodło się także rdzennym mieszkańcom Salento. Ich losy po rzymskim podboju nie są zresztą jasne. Istnieją jednak przesłanki wskazujące na trwanie ich kultury. Na III wiek przypada nawet nasilenie produkcji epigraficznej w języku messapijskim, której zanik widać dopiero w końcu II wieku p.n.e. ${ }^{27}$. Kultywowana była także miejscowa produkcja ceramiczna ${ }^{28}$, a niektóre miasta salentyńskie do początku I w. p.n.e. biły własne monety dostosowane do rzymskiego systemu menniczego, lecz z grecką ikonografią i messapijską legendą ${ }^{29}$. Odejście

${ }^{23}$ A. Marinelli, Contributo alla storia della romanizzazione del Salento, Ricerche e Studi VIII, Brindisi 1975 s. 138-139.

${ }^{24}$ M. T. Laporta, Note sui toponimi in -ano della 'Calabria' romana, [w:] La Puglia in età repubblicana. Atti del IConvegno di Studi sulla Puglia Romana, Mesagne 20-22 marzo 1986, ed. C. Marangio, Galatina 1988, s. 245-246.

${ }^{25}$ G. Camodeca, Ascesa al senato..., s. 141-146, 157-161.

${ }^{26}$ Ibidem, s. 146-147.

${ }_{27}$ Monumenta Linguae Messapicae, a cura di C. De Simone, S. Marchesini, vol. 1, Wiesbaden 2002, s. 5-11.

28 F. D'Andria, Grotta Porcinara a Punta Ristola, [w:] Leuca, Galatina 1978, s. 47.

${ }^{29}$ Szerzej zob.: M. Pawlak, Messapiowie..., s. 259-266. 
od tradycyjnej wizji całkowitego zniszczenia cywilizacji połączonego z unicestwieniem lub wysiedleniem tubylców ${ }^{30}$ rodzi pytanie o przyczyny nieobecności Messapiów w wyższych warstwach rzymskiego społeczeństwa i wśród potentatów rzymskiego południa. Zupełnie odosobniony przykładstanowi tu bowiem messapijski ród Tutorii, którego sukcesy w handlu śródziemnomorskim w końcu II wieku p.n.e. potwierdzają świadectwa z Delos i Brindisi ${ }^{31}$. Wydaje się, że przyczyn ekonomicznej, i co za tym idzie - politycznej słabości Messapiów, należy szukać wprzemianach gospodarczych zachodzących w całej Italii. Maria Jaczynowska zauważa, że rzymskie panowanie nie przyniosło południowej jej części gospodarczej pomyślności. Regres rolnictwa widoczny na terenie Apulii, Lukanii, Kalabrii i Bruttium miał być konsekwencją zaniedbania niezbędnych zabiegów kultywacyjnych (sztucznego nawadniania i osuszania bagien) ${ }^{32}$. Na Półwyspie Salentyńskim miało się to łączyć z dostrzegalną na przełomie III i II wieku p.n.e. degradacją struktury miejskiej i depopulacją obszarów ${ }^{33}$. J.-L. Lamboley uważa jednak, że ważną przyczynę ówczesnego kryzysu stanowiło związane z nową sytuacją polityczną przeorientowanie systemu gospodarczego - załamanie kontaktów handlowych z Wielką Grecją i wzrost znaczenia ośrodka w Brundisium ${ }^{34}$. Nieco zmieniają ten obraz badania wskazujące, że gospodarka południowej Apulii oparta na eksporcie wina i oliwy rozwijała się dynamicznie jeszcze na przełomie II i I wieku p.n.e., ostatecznie ulegając za-

${ }^{30}$ Dramatyczną wizję losów Messapiów, prezentowaną przez A. V. Sirago (Puglia romana..., s. 62-63), zakwestionowali S. L. Dyson (Community and Society in Roman Italy, Baltimore-London 1992, s. 27) i J. G. Burgers (Constructing Messapian Landscapes. Settlement dynamics, social organization and culture contact in the marginis of graeco-roman Italy, Amsterdam 1998, s. 277).

${ }^{31}$ I. Délos, 1751, 1753, 1754, 2123, 2612, 2638; CIL IX, 199, 200; AE 1978, 185; AE 1965, 113; AE 1980, 310; O. Parlangèli, Studi Messapici (iscrizioni, lessico, glosse e indici), Milano 1960, s. 370-374; De Simone Carlo, Su "tabaras" (femm. - a) e la diffusione di culti misteriosofici nella Messapia, „Studi Etruschi” 1982, 50, s. 189.

${ }^{32}$ M. Jaczynowska, Rzym, [w:] M. Jaczynowska, D. Musiał, M. Stępień, Historia starożytna, Warszawa 2001, s. 412.

33 J.-L. Lamboley, Recherches sur les Messapiens. IV $-I I^{e}$ siècle avant J.-C., Roma 1996, s. 486.

34 Ibidem, s. 11-12. 
łamaniu wraz z końcem republiki ${ }^{35}$. W owej prosperity, w której głównym beneficjentem było Brundisium, mieszkańcy Salento musieli mieć udział coraz bardziej ograniczony. Już bowiem w początkach pryncypatu kraj Messapiów jawi się w źródłach jako zbiedniały i wyludniony ${ }^{36}$. Ewentualne podniesienie się z upadku uniemożliwiły przemiany, jakie na przełomie I i II wieku n.e. dotknęły całą italską gospodarkę postawioną w obliczu rosnącej konkurencji ze strony zachodnich prowincji ${ }^{37}$. Na przeszkodzie przekształceniu salentyńskiej struktury rolnej stanęła przyroda. Warunki naturalne półwyspu nie sprzyjają innym uprawom poza oliwką i winoroślą. Brak naturalnych źródeł wody, skaliste wzgórza, podłoże z cienką warstwą gleby, rozległe obszary makii tworzą mało przyjazny rolnikom krajobraz. Czynniki te spowodowały zresztą zakonserwowanie antycznego systemu gospodarczego - do dziś opartego głównie na monokulturze oliwki. Mniejsze były też możliwości rozwoju hodowli tradycyjnie kojarzonej z północną Lukanią, Apulią i obszarem Murge. Niemożność przestawienia się na inne, poza sadownictwem, sfery działalności gospodarczej musiała wpłynąć negatywnie na kondycję majątkową miejscowej ludności. W tej sytuacji trudno się dziwić, że mieszkańcom Salento (bez względu na ich strukturę etniczna) zabrakło podstaw materialnych, by awansować do kręgu rzymskiej elity senatorskiej.

35 D. Manacorda, Schiavi e padroni nell'antica Puglia romana: produzione e commerci, [w:] L'archeologia dell'Adriatico dalla Preistoria al Medioevo. Atti del Convegno internazionale Ravenna, 7-8-9 giugno 2001, a cura di Fiamma Lenzi, Firenze 2003, s. 300-301; A. Tschernia, Le vin del'Italie romaine, Rome 1986, s. 167; F. Ghinatti, Aspetti dell economia agraria della Magna Grecia agli inizi dell'Impero, „Critica Storica” 1973, 10, s. 369396.

36 Strab. 6.3.5.; Plin., Nat. 3.11.100-101.

${ }^{37}$ M. Jaczynowska, op.cit., s. 529, 531. 


\section{Contribution to the picture of South Apulian elites}

(SUMmaRY)

None of Roman senator families descended from South Apulia. The reason for that should be traced in the history of those lands, originally inhabited by Messapians and conquered by Rome in the III century B.C. New Roman order led to the change of ethnical and economic structure, affecting the existing regional economy, oriented to the contacts with cities of Magna Graecia. Moreover, the character of land ownership and natural conditions of Salento Peninsula hindered both locals and new settlers from other parts of Italy wishing to grow wealthy and achieve a senator status. Prosperity through wine and olive trade, with its center in Brundisium was mainly shared by representatives of aristocratic families from outside of Apulia, i.e. Campania, Lazio or Etruria.

Małgorzata Pawlak
Instytut Historyczny, Uniwersytet Wrocławski
pawlakuwr@gmail.com

